\title{
Repeat Use of Emergency Contraceptive Pills In Urban Kenya and Nigeria
}

\begin{abstract}
CONTEXT: Little is known about the frequency and patterns of use of emergency contraceptive pills among women in urban Kenya and Nigeria.
\end{abstract}

\begin{abstract}
METHODS: To recruit women who had used emergency contraceptive pills, individuals aged 18-49 were intercepted and interviewed at shopping venues in Nairobi, Kenya, and Lagos, Nigeria, in 2011. Information was collected on 539 Nairobi and 483 Lagos respondents' demographic and behavioral characteristics, attitudes toward the method, and frequency of use. Multinomial logistic regression analyses were used to identify associations between these characteristics and frequency of pill use.
\end{abstract}

RESULTS: Eighteen percent of the women interviewed in Nairobi and 17\% in Lagos had ever used emergency contraceptive pills. On average, these respondents had used the pills less than once per month, but greater use and acceptance were seen in Lagos. In multivariate analysis, women who had sex at least once in a typical week were generally more likely than others to have used the pills 2-5 times in the last six months, rather than once or never, or to have used them six or more times. Furthermore, Lagos respondents who said their main contraceptive method was the condom, the pill or injectable, or a natural method were generally less likely than those who did not report these methods to have used the emergency pills multiple times in the last six months.

CONCLUSIONS: Repeated use of emergency contraceptive pills was not common in this sample. International Perspectives on Sexual and Reproductive Health, 2014, 40(3):127-134, doi: 10.1363/4012714

When taken after unprotected sexual intercourse, emergency contraceptive pills reduce the risk of pregnancy. These pills were designed for occasional use over indefinite periods of time and, because they are less effective than other hormonal and long-acting methods, ${ }^{1,2}$ they are not recommended as a regular method of contraception. No consensus exists for the number of times these pills can or should be taken. However, in a 2000 study on the efficacy and side effects of repeat use, ${ }^{3}$ the World Health Organization set a limit of 1-4 times per month-to date the only attempt by a normative body to define a threshold.

Increased availability of over-the-counter or behind-thecounter emergency contraceptive pills has raised concerns about repeat use and "misuse" of the product. News outlets have described an "epidemic" of repeat use worldwide in which young women were reportedly "eating [emergency contraceptives] like chocolate" in Kenya ${ }^{4}$ and "popping [them] like candy" in India. ${ }^{5}$ In Jamaica, pharmacists raised the specter of higher risks of STIs and AIDS if condom use were replaced by repeated, indiscriminate use of this method. ${ }^{6}$ Yet no one-researchers, normative bodies, health care providers, advocates or detractors-has explicitly defined what constitutes repeat use of the pills, or at what point repeat use becomes undesirable or unsafe. Strictly speaking, the method is considered safe, because research has established that there are no contraindications to or major drug interactions with this product. ${ }^{7}$ Nevertheless, concerns about increased risk of STIs and reduced contraceptive efficacy as a result of switching from condoms to repeat use of this method have been conflated with the issue of safety.

Findings from studies of emergency contraceptive pill users in Jamaica, Kenya and Ghana suggested repeat use of the method, ${ }^{8-10}$ though none offered a definition of the phenomenon, and they assessed frequency of use over different time frames. More important, these studies intercepted users in pharmacy settings, which may have resulted in the oversampling of frequent users. ${ }^{11}$ Because these pills are available over the counter in many countries, commercial pharmacies in such settings provide much more of this product than the public sector. ${ }^{12}$ For that reason, it has always been expedient to recruit users of emergency contraceptive pills at the point of sale; however, this sampling approach increases the chances of intercepting and counting women who use the method multiple times rather than women who use them once or twice a year. Representative samples of users are necessary to develop reliable and accurate profiles of method use and to determine the frequency of use. Evidence of extensive repeat use can be defined by the only benchmark available-that of exceeding the World Health Organization parameters. Demonstrating that women use emergency contraceptive pills more often than four times a month would lend some support to assertions of ineffective and inappropriate use of the method.

\section{By Dawn Chin- Quee, Kelly L'Engle, Conrad Otterness, Sarah Mercer and Mario Chen}

Dawn Chin-Quee is scientist II, Conrad Otterness was research associate I at the time this article was written and Sarah Mercer is research associate I, all in the Division of Health Services Research; Kelly L'Engle is scientist II, Division of Social and Behavioral Health Sciences; and Mario Chen is associate director, Division of Biostatistics-all at FHI 360, Research Triangle Park, NC, USA. 
To overcome limitations of previous studies and to provide robust estimates of patterns and frequency of emergency contraceptive pill use, this study employed a sampling methodology that allowed for the recruitment of a diverse group of urban women of reproductive age and a critical mass of method users. We conducted the study in Lagos, Nigeria, and Nairobi, Kenya, because in these cities, where women can purchase these pills without a prescription, anecdotal reports suggest that women use the method repeatedly. Efforts to improve the availability of emergency contraceptive pills have also been undertaken in both countries, including registration of a dedicated product, introduction of the method to public-sector and nongovernmental organizations, training and support of pill providers, raising public awareness of the method and scaling up the sustainability of services. ${ }^{13}$ Hence, Kenya and Nigeria were suitable countries for the study of repeat pill use. The study was also expected to build on and inform activities in these countries associated with the Urban Reproductive Health Initiative projects, which focus on increasing access to family planning methods and services among the urban poor.

\section{METHODS}

Sampling

Women aged 18-49 who had ever used emergency contraceptive pills constituted the target population. ${ }^{*}$ We used a multistage sampling approach to select respondents for the study. The first stage was done randomly, while the second stage targeted high-traffic shopping venues, where women of reproductive age were intercepted for screening and interviewing. In the first stage, we constructed a sampling frame of districts in Nairobi and local government areas in Lagos as the primary sampling units (PSUs). Then, since contraceptive use is known to differ by socioeconomic status, we stratified the PSUs into three income strata. ${ }^{14,15}$ We used census data to identify high-, middle- and low-income areas within Lagos and Nairobi. Classification was based on two measures: the socioeconomic status of the majority of residents in the geographic area where the main shopping venue was located within each PSU, and the socioeconomic status of the venue's clientele as determined by market research data. ${ }^{\dagger}$ In each city, we selected 25 PSUs distributed proportionally among the income strata. These PSUs were selected using proportional-to-size sampling; estimates of the number of women of reproductive age were based on census information. For the second sampling stage, we listed all high-volume open and enclosed markets and shopping centers located in each selected PSU. Using

\begin{tabular}{|lll} 
TABLE 1. Classification of women's socioeconomic status in Nairobi and Lagos \\
Classification & Nairobi & Lagos \\
\hline High & Has $\geq 2$ cars and satellite dish & Has $\geq 2$ cars and $\geq 1$ appliances \\
Middle & Has 1 car and/or satellite dish & Has 1 car and $\geq 1$ appliances \\
& Has $\geq 2$ cars, but no satellite dish & Has no car, but $\geq 1$ appliances \\
Low & Has no car and no satellite dish & Has no car and no appliances
\end{tabular}

the following criteria, we selected one venue in each unit: moderate to high traffic flow, presence of shoppers from more than one income level in mixed-income venues, and a focus on clothing and food purchases or service.

On the basis of social marketing research conducted in Kenya, ${ }^{16}$ we assumed that $10 \%$ of intercepted women would be emergency contraceptive pill users. Because our desired sample size was 500 ever-users of the method in both Nairobi and Lagos, we planned to intercept approximately 5,000 women (200 per PSU) in each city. This sample size would allow the estimation of user characteristics with adequate precision. For example, a characteristic that would be prevalent at a 50\% level would be estimated within $5 \%$ with a $95 \%$ confidence interval. This calculation assumed a low level of clustering effects (intraclass correlation of $1.5 \%)$.

\section{Data Collection}

Between August and October 2011, recruitment of participants occurred on predetermined days and at specific times, which coincided with the busiest times at shopping venues in each city. In Nairobi, interviews were conducted from Friday to Tuesday, 9 A.M. to 6 P.M. In Lagos, interviews were conducted at the same time of day, but from Friday to Wednesday, skipping Sunday, which is a slow market day. The Nairobi and Lagos offices of the market research firm Ipsos identified appropriate shopping venues and determined the socioeconomic profile of each site before conducting recruitment and interviews. Questions and the combinations of responses that determined the socioeconomic status classification of respondents were developed by Ipsos, which routinely collects such data for market surveys. In collaboration with FHI 360, this firm trained the interviewers and supervised data collection.

Interviewers used smart phones to administer the questionnaire to women who consented; they collected information on women's age (18-24, 25-34, 35-44, 45-49), marital status (married; single; separated, divorced or widowed; no response) and highest level of education completed (primary or less, secondary, college or more, no response). To assess the socioeconomic status of participants, women were asked a set of questions specific to each country, and were then classified as either low, middle or high income. In Nairobi, they were asked about the number of cars owned by household members and ownership of satellite dishes. In Lagos, in addition to the number of cars owned, women were asked whether the household had a washing machine, vacuum cleaner or home theater (Table 1).

Women were also asked about their past contraceptive use and awareness of and ever-use of emergency contraceptive pills. If a woman said that she had never used a dedicated emergency contraceptive pill, her interview was

*We excluded women younger than 18 , because they are considered minors in both countries and ethics approval was not obtained for minors.

†Because some areas served a mixed-income clientele, they could not be classified as high, middle or low income. 
terminated; further in-depth questions were administered only to users of these pills who agreed to continue the interview. These questions asked about the main contraceptive method used (condoms, the pill, injectable, emergency contraceptive pills, natural or traditional methods, IUD, implant, none, other), the frequency of sexual intercourse in a typical week, the frequency of emergency contraceptive pill use, the reason for the last use of this method, and attitudes toward repeat use and toward the method in general and vis-à-vis other methods. Attitude measures used Likert scales from "strongly agree" to "strongly disagree" (as well as a "don't know" option) to assess agreement with statements such as "Emergency contraceptive pills are as effective at preventing pregnancy as daily birth control pills" and "It's ok for a woman to take emergency contraceptive pills as many times as she needs to." For the frequency measures, participants reported numbers that were later classified into categorical variables. The remaining items were closed-ended, with options that interviewers read to participants. The main study outcomes were patterns of contraceptive use and frequency of emergency contraceptive use.

\section{Analysis}

We performed descriptive analyses of emergency contraceptive pill users' background and contraceptive use characteristics, as well as attitudes toward contraceptive methods. In addition, we documented frequency of pill use in the last 30 days, the last three months and the last six months. We then conducted bivariate and multivariate multinomial logistic regression analyses to identify associations between participant characteristics and frequency of method use (categorized as no more than once, 2-5 times and 6 or more times) in the last six months. Bivariate models included one variable at a time to obtain crude estimates of associations, while multivariate models included all examined variables to obtain adjusted estimates that accounted for potential confounding. Because the distribution of the frequency of use variable was highly skewed (more so in Nairobi than in Lagos), we used a categorical variable, which allowed us to compare women whose profiles suggested that they used these pills more as a backup method than as a regular method with women who appeared to use them regularly (i.e., at least once per month). These models account for clustering effects from the selection of women within venues.

The FHI 360 Protection of Human Subjects Committee and local institutional review boards in Kenya (Kenya Medical Research Institute) and Nigeria (National Health Research Ethics Committee) reviewed and approved the study protocol and materials.

\section{RESULTS}

\section{Sample Characteristics}

A total of 9,581 women were intercepted (4,728 and 4,853 in Nairobi and Lagos, respectively) and 6,162 were interviewed (3,033 and 3,129, respectively); the exclusion rate
TABLE 2. Percentage distribution of women who had ever used emergency contraceptive pills, by demographic and behavioral characteristics, Nairobi and Lagos, 2011

\begin{tabular}{|c|c|c|}
\hline Characteristic & $\begin{array}{l}\text { Nairobi } \\
(\mathrm{N}=539)\end{array}$ & $\begin{array}{l}\text { Lagos } \\
(\mathrm{N}=483)\end{array}$ \\
\hline \multicolumn{3}{|l|}{ Age } \\
\hline $18-24$ & 39.7 & 17.6 \\
\hline $25-34$ & 44.5 & 49.1 \\
\hline 35-44 & 14.3 & 27.3 \\
\hline $45-49$ & 1.4 & 6.0 \\
\hline \multicolumn{3}{|l|}{ Marital status } \\
\hline Married & 36.0 & 57.4 \\
\hline Single & 58.4 & 39.8 \\
\hline Separated/divorced/widowed & 5.6 & 2.4 \\
\hline No response & 0.0 & 0.4 \\
\hline \multicolumn{3}{|l|}{ Educational attainment } \\
\hline sprimary & 11.9 & 2.9 \\
\hline Secondary & 43.9 & 39.8 \\
\hline zcollege & 44.2 & 56.7 \\
\hline No response & 0.0 & 0.6 \\
\hline \multicolumn{3}{|l|}{ Socioeconomic status } \\
\hline High & 3.9 & 20.7 \\
\hline Middle & 23.2 & 52.0 \\
\hline Low & 72.9 & 27.3 \\
\hline \multicolumn{3}{|l|}{ Frequency of intercourse } \\
\hline <once a week & 18.0 & 4.4 \\
\hline Once a week & 16.5 & 11.0 \\
\hline 2-3 times a week & 16.7 & 37.7 \\
\hline$\geq 4$ times a week & 13.5 & 17.0 \\
\hline Othert & 35.3 & 30.0 \\
\hline \multicolumn{3}{|c|}{ Main contraceptive method used } \\
\hline Condoms & 30.6 & 17.4 \\
\hline Pill & 16.3 & 9.9 \\
\hline Injectable & 16.3 & 7.9 \\
\hline Emergency contraceptive pills & 14.8 & 40.8 \\
\hline Natural/traditional method & 14.8 & 15.9 \\
\hline IUD/implant & 4.8 & 2.1 \\
\hline Other & 0.0 & 5.6 \\
\hline None & 2.2 & 0.4 \\
\hline Total & 100.0 & 100.0 \\
\hline
\end{tabular}

tThese responses were nonquantifiable. Note: Percentages may not total 100.0 because of rounding.

in each city was $36 \%$. In the Nairobi sample, $88 \%$ of excluded women were outside the eligible age range, $9 \%$ refused to be interviewed and 3\% had already been interviewed. In Lagos, 53\% of excluded individuals refused to be interviewed (mostly Muslim women), 34\% were outside the age range and 13\% had already been interviewed. Of the interviewed women, $79 \%$ in Nairobi and 66\% in Lagos had heard of emergency contraceptive pills, and $18 \%$ and $17 \%$, respectively, had ever used the method. About $1 \%$ of ever-users in Nairobi and 8\% in Lagos chose to discontinue the interview after confirming their past use, which yielded corresponding analytic samples of 539 and 483 women.

Users of emergency contraceptive pills in the two cities differed on a number of characteristics. The mean ages of women in Nairobi and Lagos were 27.4 and 31.5, respectively. The majority of users (58\%) in Nairobi were single, whereas the majority (57\%) in Lagos were married (Table 2). A higher proportion of users in Lagos had completed postsecondary education ( $57 \%$ vs. $44 \%$ ), and a greater 


\begin{tabular}{|c|c|c|c|c|c|c|}
\hline \multirow[t]{2}{*}{ Measure } & \multicolumn{3}{|l|}{ Nairobi } & \multicolumn{3}{|l|}{ Lagos } \\
\hline & 30 days & 3 mos. & $6 \mathrm{mos}$. & 30 days & $3 \mathrm{mos}$. & 6 mos. \\
\hline Mean & 1.1 & 1.6 & 2.2 & 1.4 & 3.1 & 5.1 \\
\hline Median & 1 & 1 & 2 & 1 & 2 & 4 \\
\hline Range & $0-4$ & $0-20$ & $0-30$ & $0-9$ & $0-18$ & $0-36$ \\
\hline
\end{tabular}

proportion in Nairobi had no more than a primary school education ( $12 \%$ vs. $3 \%$ ). Reports of socioeconomic status support these educational differences, as the proportion of users classified as low income was much greater in Nairobi than in Lagos (73\% vs. 27\%); however, the Nairobi sample had a larger proportion of low-income women than population estimates in the socioeconomic strata from our sampling frame led us to expect (30\%). Users of emergency contraceptive pills in Lagos had sex more often than did users in Nairobi: Sixty-six percent versus 47\%, respectively, reported having intercourse at least once a week. Women in the analytic sample were similar to those in the full sample, with one exception: Users were more likely than nonusers to have attained a higher level of education (not shown).

Ever-users of emergency contraceptive pills in Lagos and Nairobi also differed by the main contraceptive method used. Condoms were the main method most commonly reported by respondents in Nairobi (31\%); emergency contraceptive pills were the most common main method among respondents in Lagos (41\%), while only $15 \%$ of Nairobi users reported them as their main method. Respondents were more likely to report that their main method was the pill or the injectable in Nairobi than in Lagos, and use of the IUD or implant was predictably low

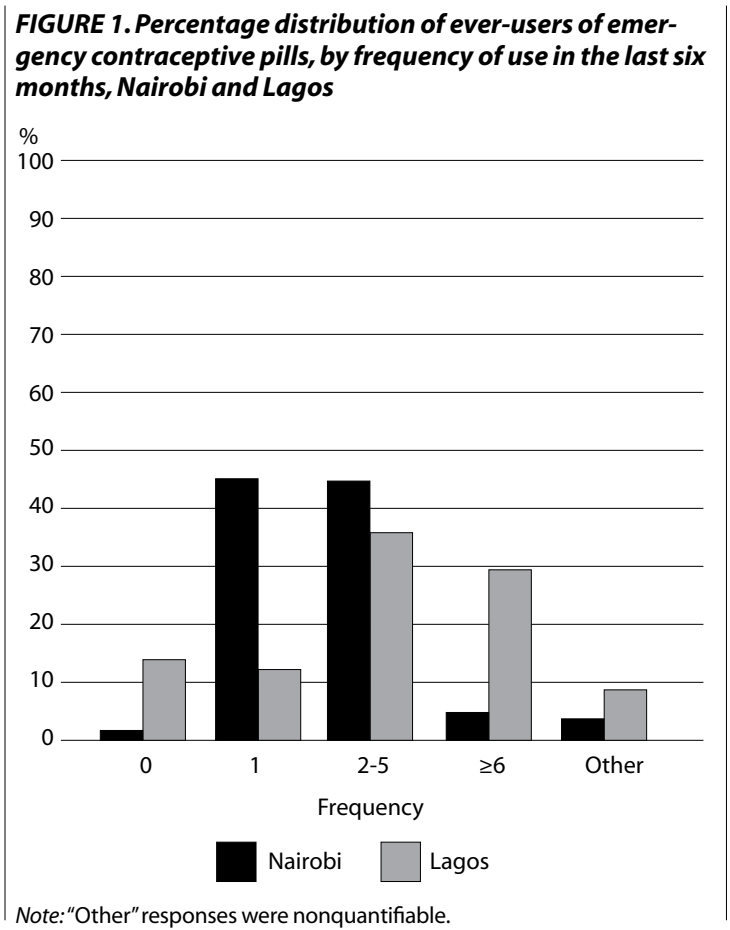

in both groups. Natural and traditional methods, which include fertility awareness methods, withdrawal and use of herbs, were cited by a similar proportion of women in the two cities.

\section{Use of Emergency Contraceptive Pills}

Thirty-three percent of respondents in Nairobi and 48\% of those in Lagos reported using emergency contraceptive pills in the last month. This pattern of greater use in the Lagos sample was seen throughout the data: While both groups averaged a single use in the last 30 days, Lagos respondents averaged five uses in the last six months, compared with two for Nairobi respondents (Table 3). The greatest proportion of emergency contraceptive pill users in Nairobi said they had taken the pills once or 2-5 times in the last six months (45\% for each-Figure 1); most of the respondents in the latter category reported using the method twice over this period (not shown), and hence use was strongly skewed to the lower end. Among respondents in Lagos, the frequency of use was more evenly distributed. Notably, the proportion of respondents who used the pills six or more times in the last six months was considerably higher in Lagos than in Nairobi (29\% vs. 5\%). When the data are considered in light of the World Health Organization parameters (i.e., no more than once per week, or up to 24 times in six months), only six respondents in Lagos $(1 \%)$ and one in Nairobi (0.2\%) used the method more often than recommended (not shown).

Regarding women's reasons for their most recent use of the method, the most commonly cited was failure to use a regular contraceptive method at a potentially unsafe time (68\% in Nairobi and 49\% in Lagos). Method or user failure-whether with a condom or the pill or injectable)-was mentioned less than $10 \%$ of the time. Partner refusal to use a condom was also reported, and respondents in Lagos were more likely to cite this reason than their Nairobi counterparts ( $21 \%$ vs. $4 \%$ )

\section{Attitudes About the Method}

Ever-users' attitudes toward emergency contraceptive pills were also assessed. Seventy-six percent of respondents in Nairobi and $78 \%$ in Lagos felt the method was as effective as regular oral contraceptive pills, and the majority (55\% in Nairobi and 59\% in Lagos) agreed that women preferred using emergency pills to using condoms. Our findings also provided insight into the greater use of the pills in the Lagos sample than in the Nairobi sample, as respondents from the former city were more likely than their counterparts in the latter city to endorse the following statements: "It is OK for a woman to take emergency contraceptive pills as many times as she needs to" (51\% vs. $21 \%$ ); "Women prefer to use emergency contraceptive pills rather than daily birth control pills" (61\% vs. 50\%); and "If the pharmacist or doctor told me it was safe, I would like to use emergency contraceptive pills as my main method of pregnancy prevention" (83\% vs. 56\%).

However, respondents in Nairobi were more likely than 


\begin{tabular}{|c|c|c|c|c|}
\hline \multirow[t]{2}{*}{ Characteristic } & \multicolumn{2}{|l|}{ Unadjusted } & \multicolumn{2}{|l|}{ Adjusted } \\
\hline & $\begin{array}{l}2-5 \text { times } \\
(\mathrm{N}=241)\end{array}$ & $\begin{array}{l}\geq 6 \text { times } \\
(\mathrm{N}=26)\end{array}$ & $\begin{array}{l}2-5 \text { times } \\
(\mathrm{N}=154)\end{array}$ & $\begin{array}{l}\geq 6 \text { times } \\
(\mathrm{N}=19)\end{array}$ \\
\hline \multicolumn{5}{|l|}{ Aget } \\
\hline $18-34$ (ref) & 1.00 & 1.00 & 1.00 & 1.00 \\
\hline $35-49$ & $1.48(0.80-2.76)$ & $0.87(0.12-6.33)$ & $2.19(1.27-3.76)^{* *}$ & $0.96(0.08-11.09)$ \\
\hline \multicolumn{5}{|l|}{ Marital status } \\
\hline Single (ref) & 1.00 & 1.00 & 1.00 & 1.00 \\
\hline Ever-married $\dagger$ & $0.56(0.36-0.86)^{* *}$ & $0.69(0.27-1.75)$ & $0.30(0.15-0.60)^{* *}$ & $0.24(0.04-1.58)$ \\
\hline \multicolumn{5}{|c|}{ Educational attainment } \\
\hline sprimary (ref) & 1.00 & 1.00 & 1.00 & 1.00 \\
\hline Secondary & $1.76(0.86-3.62)$ & $1.43(0.46-4.42)$ & $1.55(0.67-3.60)$ & $0.69(0.19-2.54)$ \\
\hline$\geq$ college & $1.29(0.60-2.78)$ & $0.34(0.09-1.30)$ & $1.15(0.48-2.76)$ & $0.13(0.02-0.76)^{*}$ \\
\hline \multicolumn{5}{|c|}{ Socioeconomic status } \\
\hline Low (ref) & 1.00 & 1.00 & 1.00 & 1.00 \\
\hline Middle/hight & $0.62(0.37-1.05)$ & $0.63(0.24-1.65)$ & $0.73(0.42-1.29)$ & $1.40(0.31-6.23)$ \\
\hline \multicolumn{5}{|c|}{ Frequency of intercourse } \\
\hline <once a week (ref) & 1.00 & 1.00 & 1.00 & 1.00 \\
\hline Once a week & $1.34(0.69-2.60)$ & $5.21(0.88-30.88)$ & $1.28(0.65-2.55)$ & $5.23(0.76-36.22)$ \\
\hline $2-3$ times a week & $1.63(0.85-3.13)$ & $10.59(1.74-64.60)^{*}$ & $2.46(1.11-5.49)^{*}$ & $15.35(1.36-173.03)^{*}$ \\
\hline$\geq 4$ times a week & $1.40(0.67-2.93)$ & $13.06(1.21-140.49)^{*}$ & $2.42(0.97-6.07)$ & $29.96(1.46-613.36)^{*}$ \\
\hline \multicolumn{5}{|c|}{ Used condoms as main method } \\
\hline No (ref) & 1.00 & 1.00 & 1.00 & 1.00 \\
\hline Yes & $1.01(0.61-1.67)$ & $0.40(0.14-1.12)$ & $0.71(0.28-1.82)$ & $0.21(0.03-1.78)$ \\
\hline \multicolumn{5}{|c|}{ Used the pill/injectable as main method } \\
\hline No (ref) & 1.00 & 1.00 & 1.00 & 1.00 \\
\hline Yes & $0.82(0.53-1.27)$ & $0.86(0.27-2.71)$ & $0.59(0.26-1.35)$ & $0.28(0.04-2.13)$ \\
\hline \multicolumn{5}{|c|}{ Used natural method as main method } \\
\hline No (ref) & 1.00 & 1.00 & 1.00 & 1.00 \\
\hline Yes & $0.77(0.48-1.23)$ & $0.91(0.19-4.42)$ & $0.56(0.24-1.34)$ & $0.39(0.04-3.51)$ \\
\hline
\end{tabular}

${ }^{*} \mathrm{p}<.05 .{ }^{* *} \mathrm{p}<.01$. †Because of small cell sizes, several categories were combined. Notes: In the unadjusted and adjusted models, the comparison groups of women who had used the pills no more than once in the last six months included 252 and 166 individuals, respectively. The overall $\mathrm{N}$ in the adjusted model was greatly reduced because of missing observations for the independent variables. ref=reference group.

those in Lagos to agree with the statements: "I would not use emergency contraceptive pills as my main method of pregnancy prevention because I am worried about HIV and other sexually transmitted infections" (64\% vs. 40\%) and "There are better ways to prevent pregnancy than using emergency contraceptive pills” (71\% vs. 58\%).

\section{Multivariate Findings}

In multivariate analyses of the Nairobi sample, associations were found between women's frequency of pill use and various characteristics (Table 4). Respondents aged 35-49 were more likely than those aged 18-34 to have used emergency contraceptive pills 2-5 times in the last six months, rather than once or never (odds ratio, 2.2). Ever-married women were less likely than single women to have used the pills 2-5 times in this period (0.3), and respondents with at least a college education were less likely than those with no more than a primary education to have used this method six or more times, instead of once or never (0.1). A clear association between increased use of the pills and greater frequency of intercourse emerged: Women who had sex 2-3 times a week were more likely than those who had sex less than once a week to have used emergency contraceptive pills 2-5 times in the last six months (2.5), and respondents who reported that or a higher frequency of intercourse had substantially increased odds of having used the pills six or more times over this period, rather than once or never (15.4 and 30.0, respectively). These multivariate results were consistent with the unadjusted findings, which suggests that confounding is not a major problem among the examined variables.

For the Lagos sample, multivariate analyses found associations with socioeconomic status, frequency of intercourse and main contraceptive method used (Table 5, page 132). High-income women were less likely than lowincome women to have used emergency contraceptive pills six or more times in the last six months, rather than once or never (odds ratio, 0.3). As seen in the Nairobi analysis, a clear pattern was found between greater use of the pills and frequency of intercourse: Compared with respondents who had intercourse less than once a week, those who had sex more often had increased odds of having used the pills 2-5 times in the last six months, instead of once or never (4.4-10.3), as well as an elevated likelihood of having used 


\begin{tabular}{|c|c|c|c|c|}
\hline \multirow[t]{2}{*}{ Characteristic } & \multicolumn{2}{|l|}{ Unadjusted } & \multicolumn{2}{|l|}{ Adjusted } \\
\hline & $\begin{array}{l}2-5 \text { times } \\
(\mathrm{N}=173)\end{array}$ & $\begin{array}{l}\geq 6 \text { times } \\
(\mathrm{N}=142)\end{array}$ & $\begin{array}{l}2-5 \text { times } \\
(\mathrm{N}=134)\end{array}$ & $\begin{array}{l}\geq 6 \text { times } \\
(\mathrm{N}=112)\end{array}$ \\
\hline \multicolumn{5}{|l|}{ Aget } \\
\hline $18-34$ (ref) & 1.00 & 1.00 & 1.00 & 1.00 \\
\hline $35-49$ & $0.42(0.26-0.70)^{* *}$ & $0.36(0.23-0.57)^{* *}$ & $0.68(0.30-1.55)$ & $0.53(0.23-1.25)$ \\
\hline \multicolumn{5}{|l|}{ Marital status } \\
\hline Single (ref) & 1.00 & 1.00 & 1.00 & 1.00 \\
\hline Ever-married $†$ & $0.62(0.42-0.94)^{*}$ & $0.68(0.39-1.20)$ & $0.59(0.29-1.22)$ & $0.86(0.37-2.01)$ \\
\hline \multicolumn{5}{|c|}{ Educational attainment } \\
\hline$\leq$ secondaryt (ref) & 1.00 & 1.00 & 1.00 & 1.00 \\
\hline zcollege & $1.14(0.78-1.67)$ & $1.54(0.75-3.15)$ & $0.95(0.44-2.08)$ & $1.52(0.53-4.32)$ \\
\hline \multicolumn{5}{|c|}{ Socioeconomic status } \\
\hline Low (ref) & 1.00 & 1.00 & 1.00 & 1.00 \\
\hline Middle & $0.82(0.50-1.36)$ & $0.91(0.48-1.74)$ & $0.58(0.24-1.38)$ & $0.41(0.14-1.22)$ \\
\hline High & $1.46(0.79-2.68)$ & $0.62(0.27-1.42)$ & $0.75(0.39-1.42)$ & $0.28(0.14-0.56)^{* *}$ \\
\hline \multicolumn{5}{|c|}{ Frequency of intercourse } \\
\hline <once a week (ref) & 1.00 & 1.00 & 1.00 & 1.00 \\
\hline Once a week & $5.63(1.81-17.52)^{* *}$ & $13.75(3.19-59.31)^{* *}$ & $4.38(1.49-12.85)^{* *}$ & $10.10(2.01-50.77)^{* *}$ \\
\hline 2-3 times a week & $10.23(2.53-41.29)^{* *}$ & $11.14(2.18-56.94)^{* *}$ & $10.29(2.49-42.48)^{* *}$ & $14.32(2.10-97.67)^{* *}$ \\
\hline$\geq 4$ times a week & $7.50(0.95-59.46)$ & $25.00(5.25-118.95)^{* *}$ & $7.76(1.18-50.95)^{*}$ & $31.58(5.56-179.41)^{* *}$ \\
\hline \multicolumn{5}{|c|}{ Used condoms as main method } \\
\hline No (ref) & 1.00 & 1.00 & 1.00 & 1.00 \\
\hline Yes & $1.48(0.83-2.65)$ & $0.93(0.45-1.92)$ & $0.63(0.27-1.43)$ & $0.37(0.18-0.78)^{* *}$ \\
\hline \multicolumn{5}{|c|}{ Used the pill/injectable as main method } \\
\hline No (ref) & 1.00 & 1.00 & 1.00 & 1.00 \\
\hline Yes & $0.60(0.31-1.18)$ & $0.28(0.12-0.64)^{* *}$ & $0.37(0.14-0.96)^{*}$ & $0.12(0.04-0.37)^{* *}$ \\
\hline \multicolumn{5}{|c|}{ Used natural method as main method } \\
\hline No (ref) & 1.00 & 1.00 & 1.00 & 1.00 \\
\hline Yes & $0.53(0.28-1.02)$ & $0.27(0.10-0.74)^{*}$ & $0.27(0.09-0.78)^{*}$ & $0.15(0.04-0.62)^{* *}$ \\
\hline
\end{tabular}

${ }^{*} \mathrm{p}<.05 .{ }^{* *} p<.01$. †Because of small cell sizes, several categories were combined. Notes: In the unadjusted and adjusted models, the comparison groups of women who had used the pills no more than once in the last six months included 128 and 70 individuals, respectively. The overall $\mathrm{N}$ in the adjusted model was greatly reduced because of missing observations for the independent variables. ref=reference group.

them six or more times over this period (10.1-31.6). In addition, Lagos respondents who reported that their main contraceptive method was the pill or injectable were less likely than others to have used emergency contraceptive pills 2-5 times in the last six months (0.4), and those who said their main method was a natural one were less likely than others to report this level of pill use (0.3). Finally, women who identified their main contraceptive method as condoms, the pill or injectable, or a natural method were also less likely than their counterparts who did not report these methods to have used emergency contraceptive pills six or more times in the last six months, rather than once or never $(0.4,0.1$ and 0.2 , respectively). These results varied from the unadjusted results only in that older respondents were less likely than younger ones to have used emergency contraceptive pills at the higher rates, while no such association was found in the multivariate analysis.

\section{DISCUSSION}

Our findings suggest that emergency contraceptive pill use has not reached "epidemic proportions" in Nairobi or Lagos, even among women who said that the pills were their main contraceptive method. The frequency of pill use, as examined over three time periods, and the small proportion of respondents who used the pills more than once a week, indicate that there was no widespread repeat use of the method in our two samples.

Users of this method reported a range of frequency of use, differed in their attitudes toward this and other methods, and demonstrated that they do not depend primarily on condoms for contraception. Nevertheless, in both cities, ever-users who had intercourse regularly in a typical week were generally more likely than others to use these pills multiple times over a six-month period, and Lagos respondents who reported that condoms, the pill or injectable, or a natural family planning method was their main method of contraception were less likely than their counterparts to report use multiple times.

This study employed a sampling methodology that facilitated the identification and recruitment of users of emergency contraceptive pills, and hence maximized the inclusion of a diverse sample of women. Our approach allowed us not only to avoid the bias described earlier in previous pharmacy-based studies, but to gain faster and 
more cost-effective access to women in the target group than we could have with labor-intensive household surveys. Because these pills are often available without a prescription, the preferred settings for purchase have usually been private-sector pharmacies and drug shops, which are more likely to be located in urban areas. Thus, given the low prevalence of users at the population level (as reported in Demographic and Health Surveys), our strategy and geographic settings provided a balance between point-of-service recruitment and a household survey, and so allowed us to collect valuable information on a heterogeneous group of users. We believe this study is the first attempt to document the frequency of emergency contraceptive pill use employing this more robust sampling strategy and standardized assessment across samples of women in urban settings.

One limitation of the study was the unexpected overrepresentation of low-income women, and the corresponding underrepresentation of high-income women, in the Nairobi sample. Despite our diligent attempt to proportionally allocate the sample across income strata, the sample of women of reproductive age and the subset of emergency contraceptive pill users who were interviewed did not reflect the census-expected proportions across socioeconomic strata. Two explanations may be considered. First, higher refusal rates are expected among higher income populations, as use of bodyguards and retreat to locked vehicles deter interviewer access in central locations as effectively as do gated grounds in household surveys. Indeed, this was reported by the interview teams, though it is not clear why it was more pronounced in Nairobi than in Lagos. Second, the measure developed by Ipsos to capture socioeconomic status may not have accurately reflected income levels, given the mixing of such levels at many of these shopping venues. While we may not have captured the census-based economic mix in Nairobi, we did not find evidence of confounding effects from this imbalance. No associations were found between socioeconomic status and frequency of pill use among Nairobi respondents, so it is unlikely that our analyses were affected by the disproportionate distribution across economic strata.

Another limitation worth noting is that a small number of Nairobi respondents reported using the pills six or more times in the last six months, and this may have affected the reliability of the associations reported for this group. We chose to examine three frequency-of-use categories instead of combining them, because we believe it is important to identify any differences across these categories and to maintain the comparability of the results between the two cities. Finally, because of small cell sizes in several age-groups in both cities, we used two instead of four agegroups in the regression analyses to improve the estimation of possible associations.

Even though the comparison between the Nairobi and Lagos samples should be considered descriptive and exploratory, our findings suggest important differences in the types of women and patterns of use among emergency contraceptive pill users that may be relevant when considering programs in different settings. For example, information, education and communication materials, as well as behavioral interventions, would have to be tailored for places like Lagos, where a significant proportion of married women use the pills (a group that typically uses regular and more effective contraceptive methods), and where attitudes toward the method may be more amenable to frequent use than in Nairobi.

Our results show that while noteworthy proportions of women who had used emergency contraceptive pills said they used them as their main method (15\% in Nairobi and $41 \%$ in Lagos), the average use was between two and five times in a six-month period, which amounts to less than once per month. Nevertheless, we found a robust association between frequency of intercourse and frequency of emergency contraceptive pill use, suggesting that guidance should be provided to women who rely on the method as their main or regular contraceptive. Although some users may be better served by a more regular or longer-acting contraceptive method, ${ }^{10}$ our findings suggest that this may apply to a minority of users.

The media have often dominated the debate on repeat use of emergency contraceptive pills. Rather than allow anecdotal accounts and unproven or subjective statements to shape the debate, an evidence-based approach that assesses medical safety and contraceptive efficacy should be used to define parameters for repeat use of the pills and to provide recommendations to women and men who rely on the method. Thus, if regular use of emergency contraceptive pills is shown to be safe, efficacious and acceptable in rigorous clinical research, this would help establish the appropriate frequency of use and define the circumstances under which a woman can use the method (or a similar product) on demand.

\section{REFERENCES}

1. International Consortium for Emergency Contraception (ICEC), Clinical summary: emergency contraceptive pills, 2013, <http:// www.cecinfo.org/custom-content/uploads/2014/01/ICEC_ClinicalSummary_2013.pdf>, accessed Jan. 22, 2014.

2. World Health Organization, Emergency contraception, 2012, <http://www.who.int/mediacentre/factsheets/fs244/en/>, accessed Apr. 30, 2014.

3. United Nations Development Programme et al., Efficacy and side effects of immediate postcoital levonorgestrel used repeatedly for contraception, Contraception, 2000, 61(5):303-308.

4. Okwemba A and Anyona J, Having fun with morning-after pills, Daily Nation (Nairobi, Kenya), May 13, 2004, pp. 25-26.

5. Rai S, India: popping morning after pills like candy, GlobalPost.com, June 28, 2010, <http://www.globalpost.com/dispatch/india/100625/ morning-after-pill-sexual-freedom-health>, accessed July 17, 2014.

6. Blair L, "Morning after" scare: Postinor 2 abuse worries pharmacists, Jamaica Gleaner (Kingston), Nov. 30, 2003.

7. ICEC, Emergency contraception: questions and answers for decision-makers, 2013, <http://www.cecinfo.org/custom-content/ uploads/2014/01/ICEC_QandAforDecisionmakers_2013.pdf>, accessed Jan. 22, 2014.

8. Chin-Quee DS et al., Bridging emergency contraceptive pill users to regular contraception: results from a randomized trial in Jamaica, 
Contraception, 2010, 81(2):133-139.

9. Keesbury J, Morgan G and Owino B, Is repeat use of emergency contraception common among pharmacy clients? Evidence from Kenya, Contraception, 2011, 83(4):346-351

10. Chin-Quee D et al., Bridge over troubled waters: considerations in transitioning emergency contraceptive users to hormonal methods, Contraception, 2012, 85(4):363-368

11. Raymond E, Westley E and Trussell J, Repeat use of emergency contraception in Kenya, letter to the editor, Contraception, 2011, 84(6):655-656.

12. Westley E, Rich S and Lawton H, The Unfinished Agenda: Next Steps to Increase Access to Emergency Contraception, New York: ICEC, 2014, <http://www.cecinfo.org/custom-content/uploads/2014/01/ICEC_ Next-Steps-WEB_2014.pdf>, accessed Jan. 22, 2014.

13. Hossain SMI et al., ECP Handbook: Introducing and Mainstreaming the Provision of Emergency Contraceptive Pills in Developing Countries, FRONTIERS Manual, Washington, DC: Population Council, 2009, <http://www.popcouncil.org/uploads/pdfs/frontiers/Manuals/FR_ ECPHandbook.pdf>, accessed Aug. 7, 2014

14. National Population Commission (NPC) and ICF International, Nigeria Demographic and Health Survey, 2013, Abuja, Nigeria: NPC; and Rockville, MD, USA: ICF International, 2014.

15. Kenya National Bureau of Statistics (KNBS) and ICF Macro, Kenya Demographic and Health Survey, 2008-2009, Calverton, MD, USA: KNBS and ICF Macro, 2010.

16. Population Services International (PSI), Kenya (2009): Family Planning TRaC Study examining the use of emergency contraceptive methods among women aged 18-30 years, Social Marketing Research Series, Nairobi, Kenya: PSI, 2009.

\section{RESUMEN}

Contexto: Poco se sabe sobre la frecuencia y patrones de uso que las mujeres en zonas urbanas de Kenia y Nigeria hacen de las píldoras de anticoncepción de emergencia.

Métodos: Para reclutar mujeres que habían usado píldoras de anticoncepción de emergencia, en 2011 se interceptó y entrevistó a mujeres en edades de 18 a 49 años en centros comerciales en Nairobi, Kenia y Lagos, Nigeria. Se recolectó información sobre características demográficas y conductuales, actitudes hacia el método y frecuencia de uso de 539 personas entrevistadas en Nairobi y 483 en Lagos. Se utilizaron análisis de regresión logística multinomial para identificar asociaciones entre estas características y la frecuencia en el uso de la anticoncepción de emergencia.

Resultados: Dieciocho por ciento de las mujeres interceptadas en Nairobi y 17\% en Lagos habían usado alguna vez píldoras anticonceptivas de emergencia. En promedio, estas personas entrevistadas habían usado las píldoras menos de una vez por mes, pero se observó un mayor uso y aceptación en Lagos. En los análisis multivariados, las mujeres que tenían relaciones sexuales al menos una vez en una semana típica, tuvieron en general una mayor probabilidad que otras de haber usado las píldoras de 2 a 5 veces en los últimos seis meses, en vez de una sola vez o nunca, o de haberlas usado seis o más veces. Además, las personas entrevistadas en Lagos que dijeron que su principal método anticonceptivo era el condón, la píldora o el inyectable, o un método natural, en general tuvieron una menor probabilidad que quienes no reportaron el uso de estos métodos de haber usado las píldoras de emergencia en múltiples ocasiones en los últimos seis meses.

Conclusiones: El uso repetido de las píldoras de anticoncepción de emergencia no fue común en esta muestra.

\section{RÉSUMÉ}

Contexte: La fréquence et les tendances du recours à la pilule contraceptive d'urgence parmi les femmes du Kenya et du Nigéria urbains ne sont guère documentées.

Méthodes: Pour le recrutement d'utilisatrices de la pilule contraceptive d'urgence, des femmes de 18 à 49 ans ont été abordées et interviewées dans les centres commerciaux de Nairobi (Kenya) et de Lagos (Nigéria) en 2011. Une information relative aux caractéristiques démographiques et comportementales de 539 et 483 répondantes à Nairobi et à Lagos, respectivement, à leurs attitudes à l'égard de la méthode et à la fréquence de leur recours à la méthode, a été collectée. Les associations entre ces caractéristiques et la fréquence du recours à la pilule ont été identifiées par analyses de régression logistique multinomiale.

Résultats: Des femmes abordées à Nairobi et à Lagos, $18 \%$ et $17 \%$, respectivement, avaient jamais eu recours à la pilule contraceptive d'urgence. En moyenne, ces répondantes $y$ avaient eu recours moins d'une fois par mois, bien qu'un plus haut niveau d'usage et d'acceptation aient été observés à Lagos. Dans l'analyse multivariée, les femmes qui avaient des rapports sexuels au moins une fois par semaine ordinaire se sont révélées généralement plus susceptibles que les autres d'avoir eu recours à la pilule deux à cinq fois au cours des six derniers mois écoulés, plutôt qu'une fois ou jamais, ou au moins six fois. De plus, les répondantes de Lagos ayant indiqué comme méthode de contraception principale le préservatif, la pilule ou l'injectable, ou une méthode naturelle, se sont révélées généralement moins susceptibles que celles n'ayant pas déclaré ces méthodes d'avoir eu recours à la pilule d'urgence à plusieurs reprises durant les six derniers mois.

Conclusions: Le recours répété à la pilule contraceptive d'urgence ne s'est pas avéré courant dans cet échantillon.

\section{Acknowledgments}

This research was supported by a grant from Family Care International, the host organization for the International Consortium for Emergency Contraception.

Author contact:dchin-quee@fhi360.org 